УДК 621.791.05:622.692

ПОВЫШЕНИЕ ПРОЧНОСТИ СВАРНОГО СОЕДИНЕНИЯ

ИЗ СТАЛИ 12×17 ПРИМЕНЕНИЕМ ВИБРАЦИОННОЙ

ОБРАБОТКИ

\title{
IMPROVING THE STRENGTH PROPERTIES OF THE WELDED JOINT FROM 12X17 (12CR17) STEEL BY APPLICATION OF VIBRATION TREATMENT
}

А.М. Файрушин, А.В. Журихина, В.А. Бычков, Д.Р. Салимзянова

Уфимский государственный нефтяной технический университет, г. Уфа, Российская Федерация

Airat M. Fayrushin, Anastasia V. Zhurikhina, Vladimir A. Bychkov, Diana R. Salimzyanova

Ufa State Petroleum Technological University, Ufa, Russian Federation e-mail: otsk@ rusoil.net

Аннотация. В современных условиях нефтепереработки, связанных с растущими требованиями к качеству выпускаемой продукции и обеспечению безопасности процессов, усложняются условия работы оборудования, и расширяется номенклатура применяемых материалов. Значительная часть оборудования, которое используется для осуществления высокотемпературных процессов переработки в сероводородных и окислительных серосодержащих средах, изготавливается из жаропрочных хромистых ферритных сталей типа $12 \times 17,08 \times 17$ и т.п., технологический процесс сварки которых достаточно сложен, ввиду низкой технологической прочности сварных соединений. Также недостатком является то, что данные стали склонны к отпускной хрупкости, в том числе из-за наличия высокого уровня остаточных напряжений в сварном шве. 
Вибрационная обработка в процессе сварки позволяет в определенной мере управлять полем остаточных напряжений и получения более однородного структурного состояния в зоне шва, уменьшая его отрицательное влияние на прочность и работоспособность конструкции. Предлагаемый метод вибрационной обработки в процессе сварки позволяет снизить уровень остаточных напряжений, а также улучшить прочностные свойства металла шва.

В данной статье рассмотрено влияние вибрационной обработки в процессе сварки на качество формы шва, геометрические отклонения сварных соединений, механические свойства сварного шва, выполненных из стали типа $12 \times 17$. Проведена оценка качества формирования сварного шва, выполненного с применением сопутствующей вибрации, с использованием объемной лазерной диагностики формы поверхности сварного шва, а также качественная оценка напряженного состояния. Установлено влияние вибрационной обработки на повышении прочности и снижение вероятности разрушения сварных конструкций.

Abstract. In modern refinery conditions, connecting with growing requirements for the quality of products and securing process safety, the equipment operating conditions are becoming more complicated and the range of materials used is expanding. A significant part of the equipment that is used to carry out high-temperature processing in hydrogen sulfide and oxidizing sulfurcontaining environments is made of heat-resistant chromium ferritic steels of the $12 \times 17,08 \times 17$, etc. types, the welding process of which is rather complicated since the low technological strength of welded joints. Likewise, the drawback of these steels are temper brittleness, including due to the presence of a high level of residual stresses in the weld.

Vibration treatment in the welding process allows to a certain extent to control the field of residual stresses and obtain a more uniform structural state in the weld zone, reducing its negative effect on the strength and performance of the structure. The proposed method of vibration treatment during welding allows to reduce the 
level of residual stresses, as well as to improve the strength properties of the weld metal.

In this article was considered the influence of vibration processing in the welding process on the quality of the weld shape, geometric deviations of welded joints, mechanical properties of a welded seam made of $12 \times 17$ steel. An assessment of the quality of the formation of a welded joints made with the use of accompanying vibration, using volumetric laser diagnostics of the shape of the weld joint surface, as well as a qualitative assessment of the stress state has been carried out. The effect of vibration treatment on increasing the strength and reducing the probability of fracture of welded structures has been established.

Ключевые слова: вибрационная обработка; остаточные напряжения; сварные соединения; растяжение; предел прочности; разность главных механических напряжений; коэффициент концентрации механических напряжений

Keywords: vibration treatment; residual stresses; welded joints; tension; ultimate strength; difference between the main mechanical stresses; coefficient of concentration of mechanical stresses

В настоящее время в нефтегазовом производстве, связанном с растущими требованиями к качеству продукции и обеспечению безопасности процессов, условия работы оборудования становятся сложнее, а ассортимент применяемых материалов расширяется. Значительная часть оборудования, в особенности используемого для осуществления высокотемпературных процессов переработки в окислительных средах, изготавливается из жаропрочных высокохромистых сталей $12 \times 17$.

В связи с высокой хрупкостью ферритных сталей типа $12 \times 17,08 \times 17$, ГОСТ 5632 не регламентирует ее ударную вязкость, а оговаривает лишь минимально допустимые значения прочности и пластичности. Высокая чувствительность стали к надрезу затрудняет еe применение для 
изготовления металлоконструкций и оборудования, работающего в условиях ударного и низкопеременного нагружения, низких климатических температур. Такие ферритные стали используют для изготовления ненагруженных устройств и изделий. При сварке под воздействием термического цикла сталь $08 \times 17$ Т дополнительно может охрупчиваться в зоне термического влияния. Это вызывает необходимость усложнения техники и технологии сварки: использование предварительного подогрева кромок и последующую термическую обработку сварных соединений.

Недостатками высокохромистых сталей ферритного класса также являются склонность к росту зерна при нагреве, склонность к охрупчиванию в интервале температур отпуска 400-500 ${ }^{\circ} \mathrm{C}$, трудности в обеспечении свариваемости, склонность к межкристаллитной коррозии, невысокие прочностные свойства $[1,2]$

Проблема раннего выхода оборудования из строя особенно актуальна в нефтехимической и нефтеперерабатывающей промышленности. При несвоевременном снятии остаточных напряжений с помощью термообработки велика вероятность образования холодных трещин, что, в конечном итоге, может привести к разрушению конструкции.

Актуальным является поиск менее энергоемких, чем термическая обработка, и экологически чистых технологий снятия остаточных напряжений при изготовлении оборудования нефтегазопереработки. Одним из активно рассматриваемых на сегодняшний день является способ сопутствующей вибрационной обработки. Вибрационная обработка позволяет в определенной мере управлять полем остаточных напряжений и получением более однородного структурного состояния в зоне шва, уменьшая его отрицательное влияние на прочность и работоспособность конструкции [3-7].

Для того, чтобы исследовать данное направление, необходимо провести анализ существующей технологии сварки хромистых ферритных сталей и способов снятия остаточных напряжений, а также оценить влияние режимов 
вибрационной обработки в процессе сварки на распределение остаточных деформаций и механические свойства сварного соединения, изготовленного из хромистых сталей ферритного класса.

В качестве материала для испытаний была выбрана сталь $12 \times 17$ как одна из наиболее часто применяемых жаростойких марок стали данной группы применяемая для изготовления сварного нефтегазового оборудования.

С целью практического изучения влияния сопутствующей вибрационной обработки на напряженно-деформированное состояние сварной конструкции были проведены эксперименты и сварены между собой пластины длиной 300 мм, шириной 125 мм и толщиной 5 мм, изготовленные из стали $12 \times 17$. Сварку производили в лабораторных условиях, ручную дуговую покрытыми электродами, марка электродов ЦЛ11 диаметр 3 мм. Сварка проводилась на следующих режимах: сила тока 7585 А, напряжение 22-26 В. Режимы сварки и обработки исследуемых сварных образцов приведены в таблице 1.

Таблица 1. Режимы сварки и обработки исследуемых сварных образцов

\begin{tabular}{|c|lcccc|}
\hline $\begin{array}{c}\text { Тип } \\
\text { образца }\end{array}$ & \multicolumn{4}{|c|}{ Вид обработки в процессе сварки } \\
\hline 1 & $\begin{array}{l}\text { Вибрационная } \\
0,4-0,6 \text { мм) }\end{array}$ & обработка & (частота 50 & Гц, & амплитуда \\
\hline 2 & Без обработки & & \\
\hline 3 & По технологии (предварительный подогрев $28^{\circ} \mathrm{C}$ ) \\
\hline
\end{tabular}

Механика вибрационного воздействия при низкочастотных колебаниях представляет собой динамический процесс и определяется параметрами перемещений, определяемых частотой колебаний и траекторией движений, а также силовых взаимодействий определяемых амплитудой колебаний. Для создания виброколебаний в процессе сварки был использован вибростол. Управление режимом виброобработки осуществляли амплитудным методом. 
С целью определения качества формирования сварного шва в поле вибрационного воздействия после сварки образцы подвергали анализу с использованием объемной лазерной диагностики формы поверхности сварного шва с применением программно-аппаратного комплекса LST [8], который позволяет сканировать форму шва на длине до 300 мм (рисунок 1).

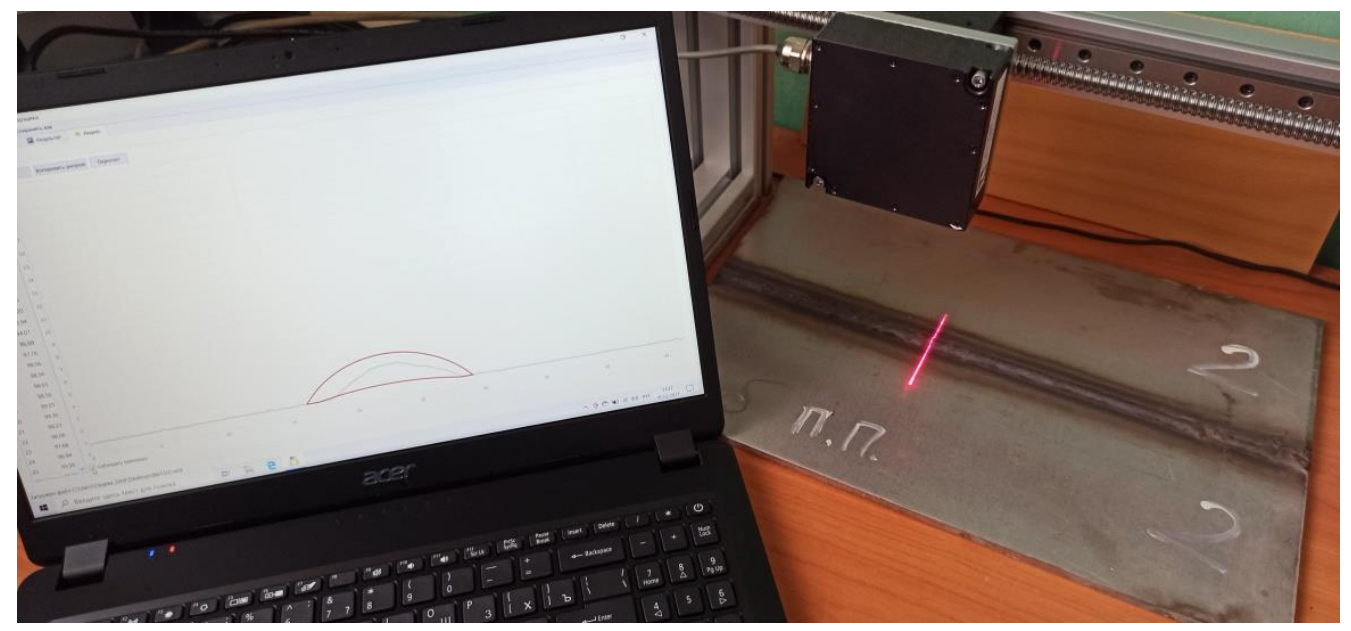

Рисунок 1. Фото сканирования контрольного сварного образца

На рисунке 2 представлены полученные цифровые реплики сварных соединений. Как видно из рисунка 2, значимых дефектов формы сварного шва (трещины, поры, подрезы) на контрольных образцах нет. Вибрационная обработка в процессе сварки позволяет формировать сварной шов требуемого качества.

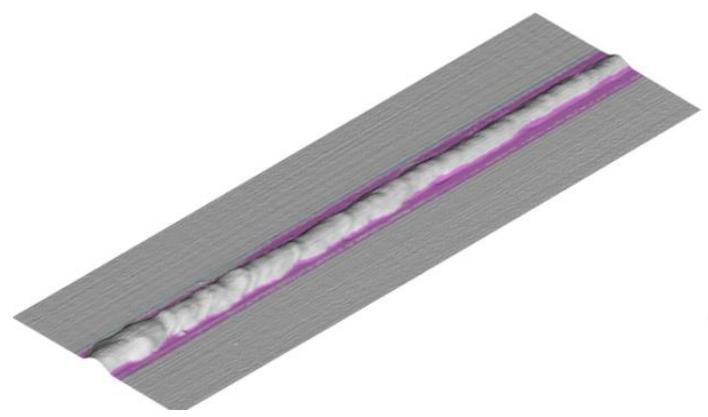

a)

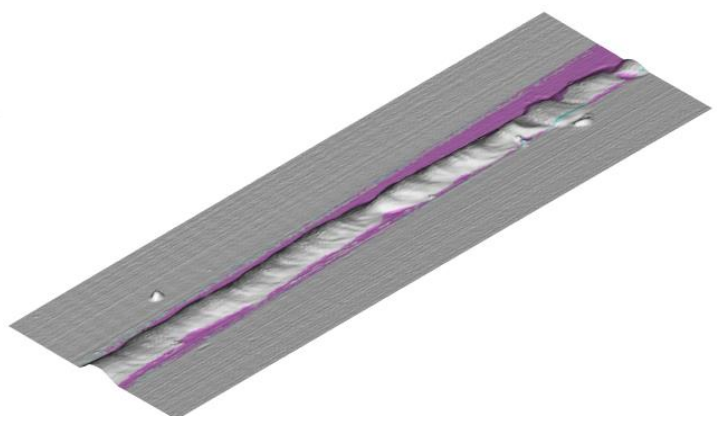

б)

а) без вибрационной обработки;

б) в сопутствующей вибрационной обработкой

Рисунок 2. 3D реплика сварного соединения для разных условий обработки 
Проведенный измерительный контроль сварных образцов показал наличие сварочных деформаций пластин (рисунок 3 ). Наличие деформаций сварных конструкций является известным фактом, они носят наследственный технологический характер [9] и практически наблюдаются в большинстве сварных конструкций в большей или меньшей степени. С целью определения влияния вида обработки при сварке на образцах был проведен замер величины прогиба на базе длины 300 мм. Результаты замера наглядно представлены на рисунке 4.
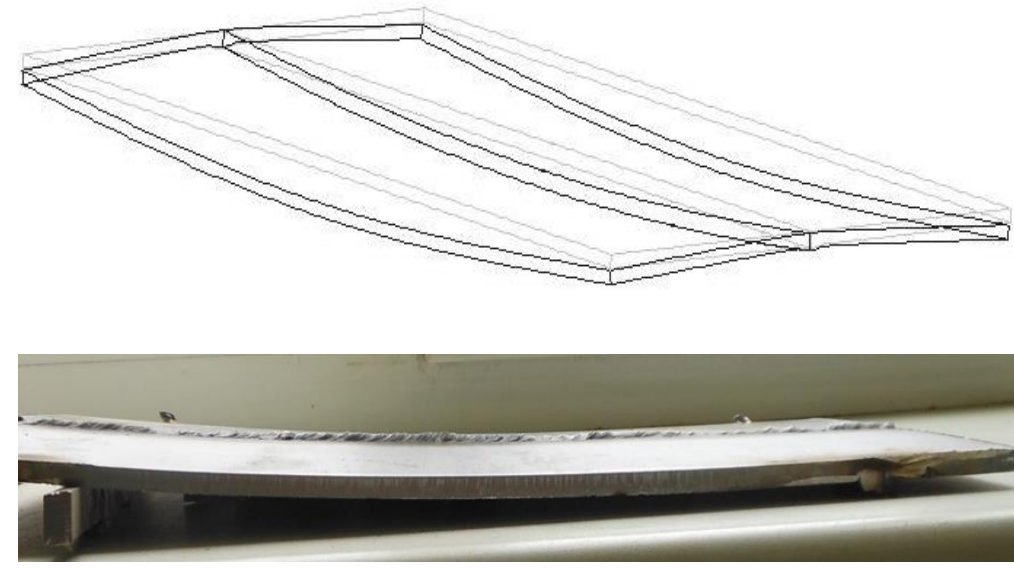

Рисунок 3. Схем прогиба и фото деформированных пластин после сварки

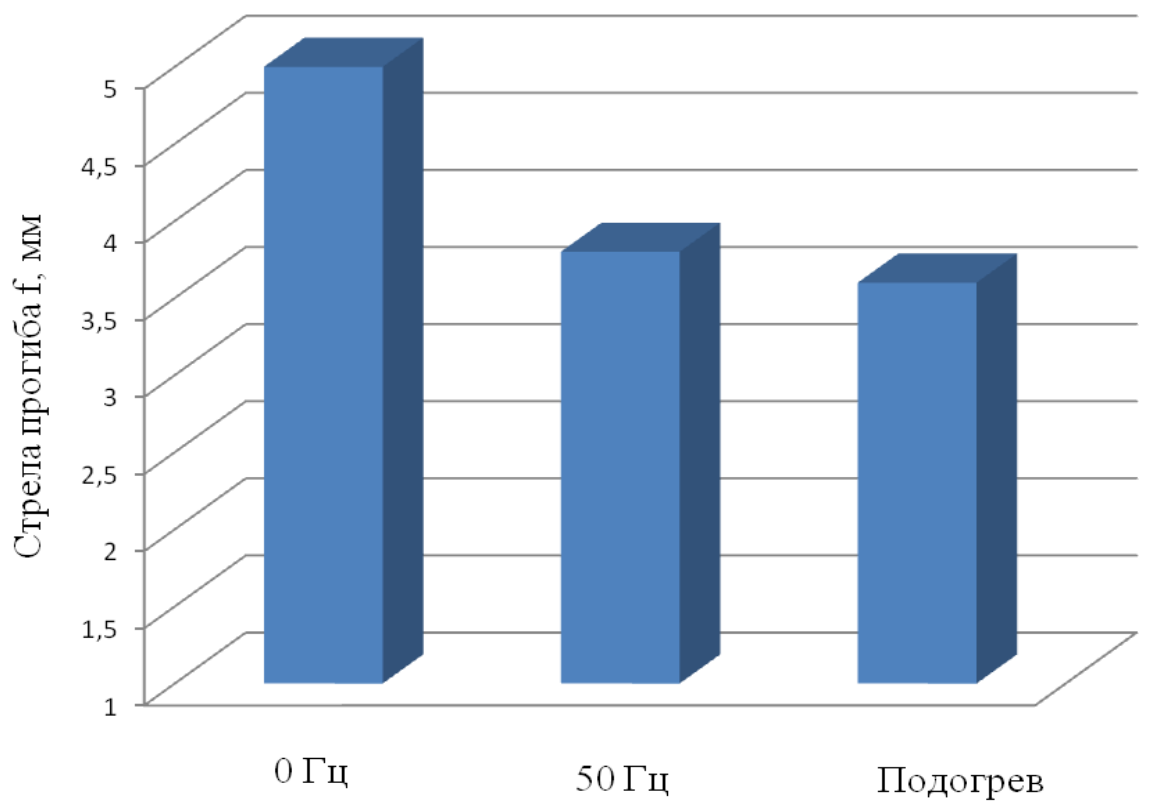

Тип обработки

Рисунок 4. Влияние разных условий обработки в процессе сварки на деформированное состояние свариваемых пластин 
Как видно из результатов замеров, вибрационная обработка снижает величину стрелы прогиба. На частоте 50 Гц и предварительном подогреве эти отклонения на $25 \%$ и $28 \%$ меньше соответственно, чем у образца, сваренного без виброобработки.

Исследования на растяжение плоских образцов в соответствии с ГОСТ 6996 из стали 12×17 были проведены на разрывной машине ИР 5113-100, скорость деформирования 2 мм/мин, температура испытания $20{ }^{\circ} \mathrm{C}$, ширина образца - 10 мм, толщина - 5 мм, длина - 200 мм. По результатам испытаний построены диаграммы зависимости предела прочности и текучести металла сварного шва от вида обработки во время и после сварки.

При испытаниях сварных соединений на растяжение разрушение образцов происходило по основному металлу. Это даёт основание считать, что при данных режимах сварки при сопутствующей вибрационной обработке как металл шва, так и металл околошовной зоны имеют прочностные характеристики не ниже, чем основной металл. Результаты испытаний образцов для определения прочности металла сварного шва приведены на рисунках 5 и 6.

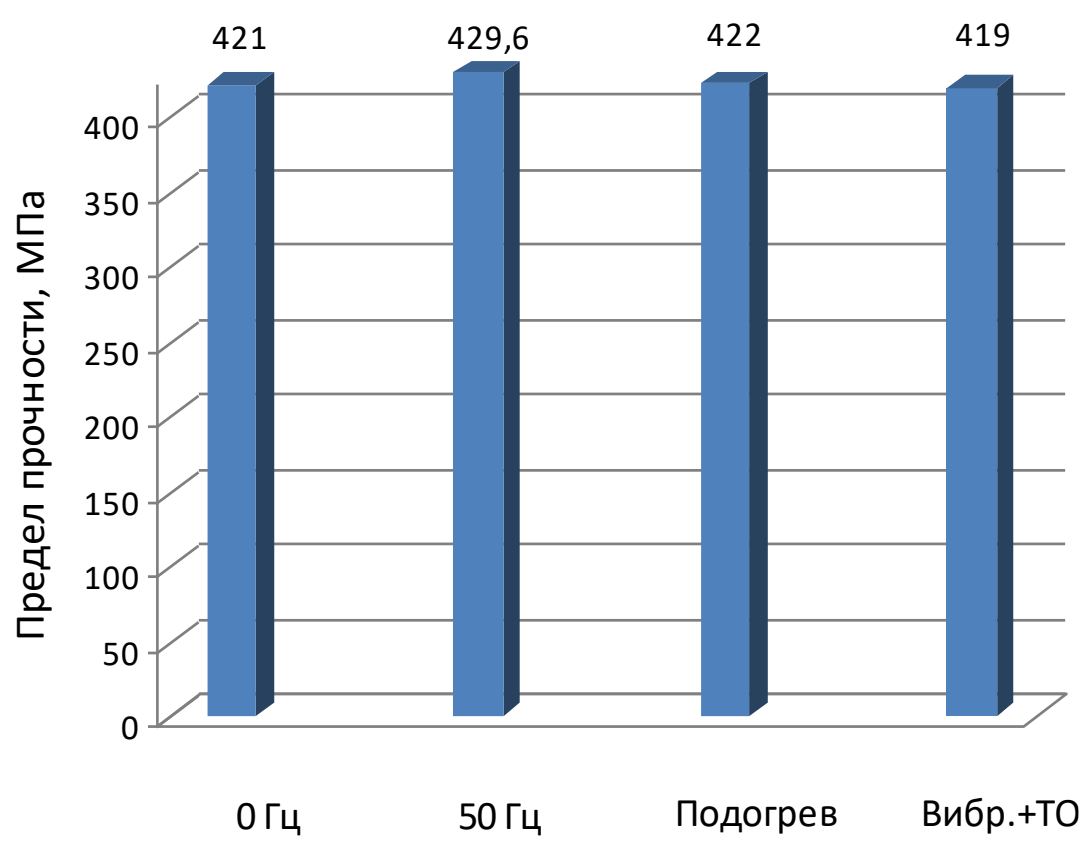

Рисунок 5. Средние значения предела прочности сварного шва 


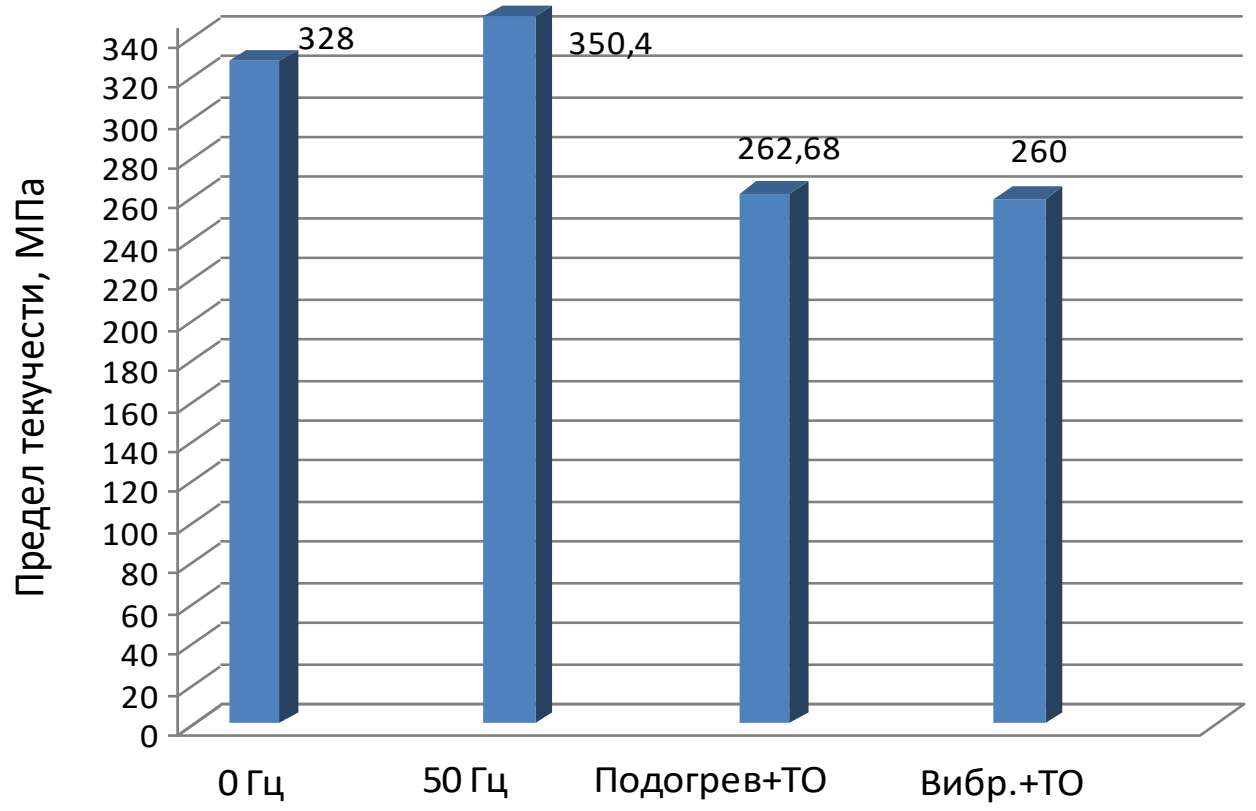

Рисунок 6. Средние значения предела текучести

Из рисунка 5 видно, что виброобработка при частоте 50 Гц повышает прочностные характеристики металла шва на 2 \%, а при предварительном подогреве повышает прочностные характеристики металла шва на $3 \%$. Повышение прочностных характеристик металла незначительно и можно объяснить возможным получением мелкозернистой структуры металла шва при проведении вибрационной обработки

Результаты испытания образцов показывают, что виброобработка при частоте 50 Гц повышает предел текучести металла шва на 7 \%, предварительный подогрев с последующей термической обработкой понижает предел текучести металла шва на 20 \%; сопутствующая вибрационная обработка с последующей термической обработкой понижает предел текучести металла шва на 21 \%. Результаты испытания образцов показывают, что в целом применение вибрационной обработки благоприятно сказывается на механических свойствах сварных соединений.

Далее были проведены замеры твердости металла на твердомере Rockwell 574R. Замеру подвергался сварной шов в горизонтальном положении с интервалом 1,5 мм. Были получены результаты замеров твердости, которые приведены на рисунке 7. 


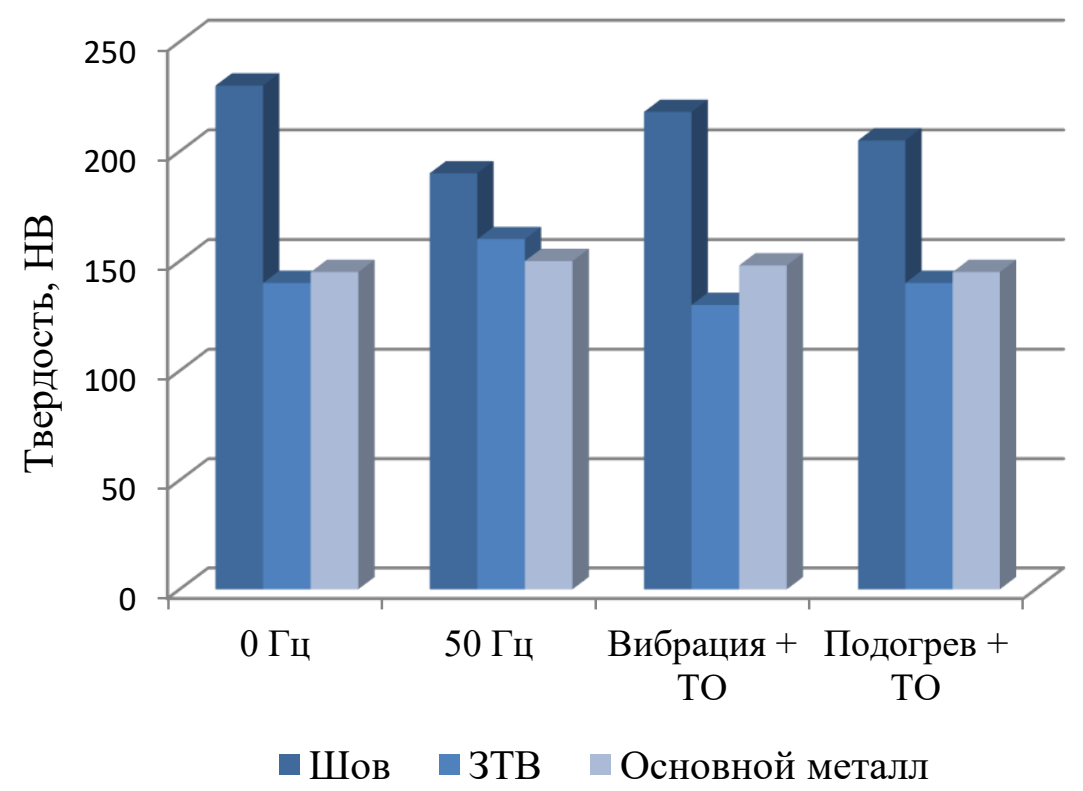

Рисунок 7. Диаграмма твердости образцов

Испытание на ударную вязкость в зоне шва производили на образцах с V-образным надрезом (тип XI ГОСТ 6996-66). Температура испытаний составляла $20^{\circ} \mathrm{C}$, ширина образца 10 мм, высота рабочего сечения 5 мм.

Испытания проводились на башенном копре модели Instron CEAST 9340.

По результатам испытания построена диаграмма зависимости ударной вязкости металла сварного шва от вида обработки во время сварки (рисунок 8).

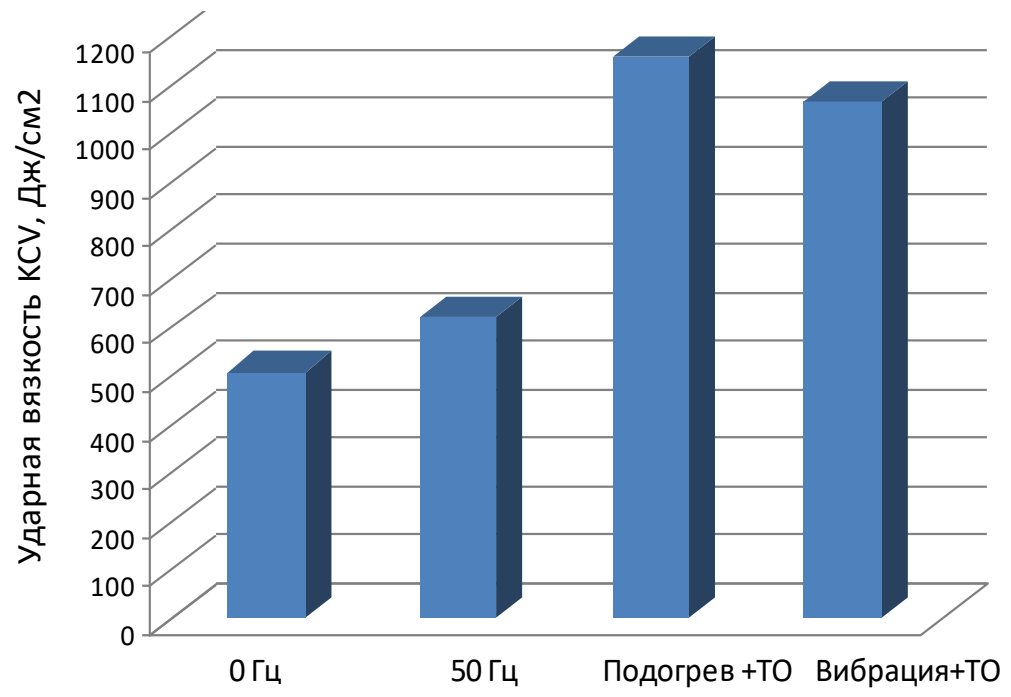

Рисунок 8. Диаграмма зависимости ударной вязкости металла сварного шва от вида обработки во время и после сварки 
Проведенные испытания ударной вязкости позволили установить влияние вибрационной обработка на ударную вязкость металла сварного шва. При вибрационной обработке показатель ударной вязкости больше, чем без обработки. В диапазоне амплитуд 0,4-0,6 мм при постоянной частоте вибрации 50 Гц ударная вязкость увеличивается на 19 \%. При тех же значениях амплитуды и частоты, но с применением последующей термической обработкой вместо предварительного подогрева показатель ударной вязкости уменьшается на $16 \%$.

Одной из известных проблем хромистых ферритных сталей является склонность к отпускной хрупкости, в связи с чем нами было принято решение о проведении оценки напряженного состояния сварных соединений до операции термической обработки.

Исследование проводили с применением сканера-дефектоскопа магнитоанизотропного «Комплекс 2.05». Сканированию подвергали сварные соединения, сваренные с применением вибрационной обработки и без нее. Шаг сетки по оси х и по оси у составлял 20 мм. Сварной шов располагался в центре. Результаты сканирования представлены на рисунках 9 и 10.

В таблице 2 представлена статистика карт разности главных механических напряжений (РГМН).

Полученные результаты замера напряженного состояния сварных соединений показывают, что вибрационная обработка в процессе сварки позволяет снизить уровень внутренних напряжений, а также почти в 2 раза снизить коэффициент концентрации механических напряжений. 


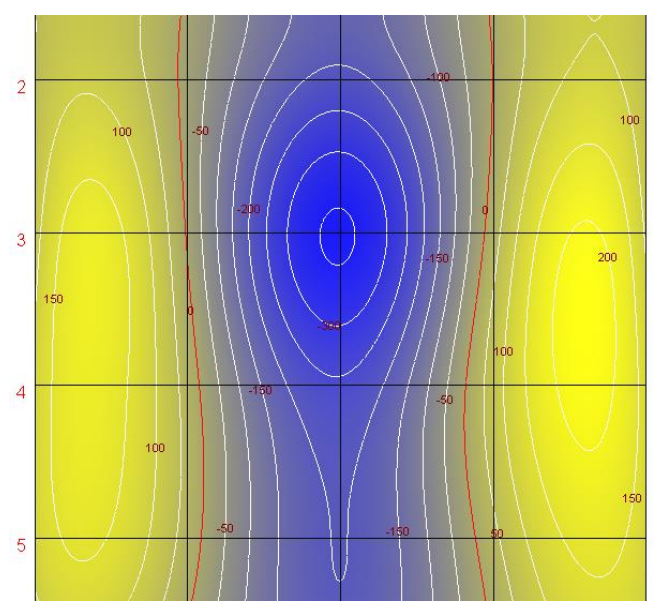

a)

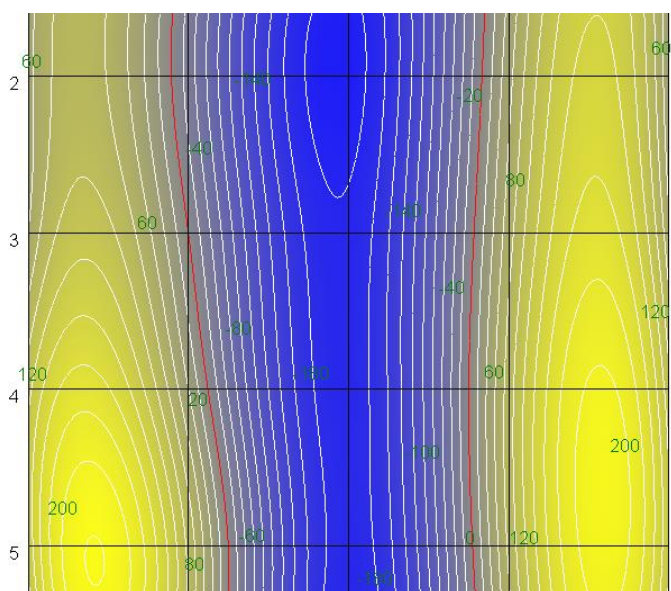

б)

а) без вибрационной обработки;

б) с сопутствующей вибрационной обработкой

Рисунок 9. Картограмма изостресс РГМН для разных условий обработки

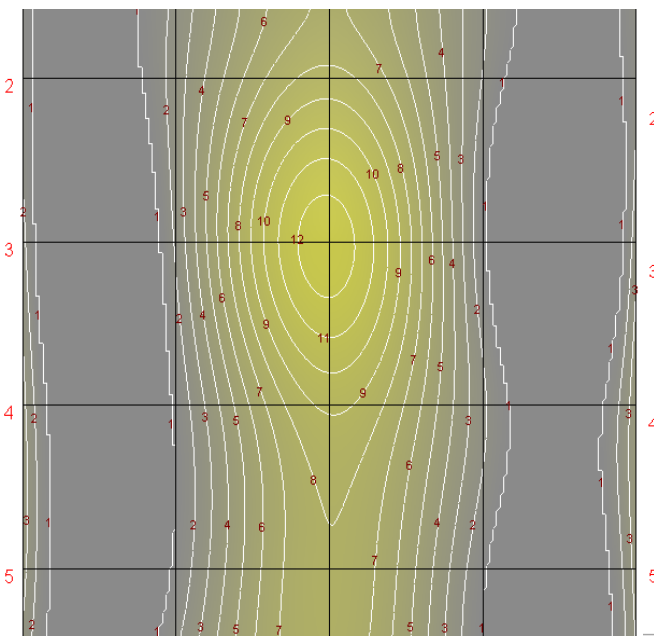

a)

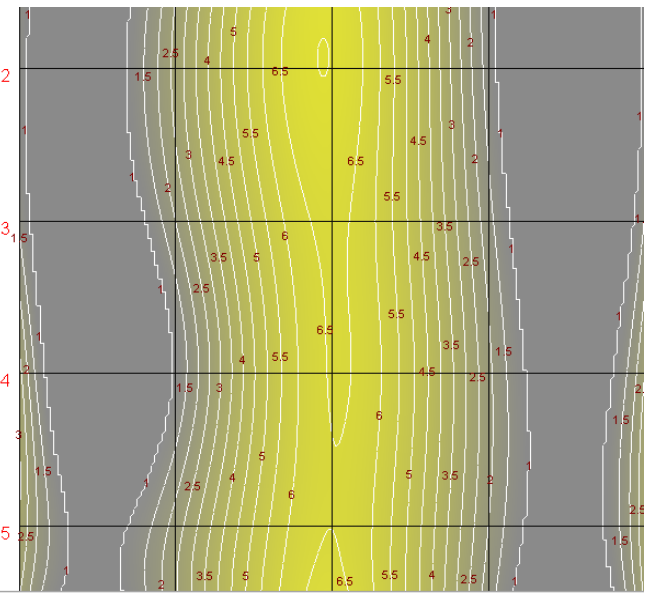

б)

а) без вибрационной обработки;

б) с сопутствующей вибрационной обработкой

Рисунок 10. Картограмма изостресс КМН для разных условий обработки

Таблица 2. Статистика карт РГМН

\begin{tabular}{|c|c|c|c|c|c|}
\hline $\begin{array}{c}\text { Вид обработки } \\
\text { образца }\end{array}$ & $\begin{array}{c}\text { МО } \\
\text { [у.е.] }\end{array}$ & СКО & $\begin{array}{c}\text { Дисперсия, } \\
\mathrm{D}_{\text {i }}\end{array}$ & $\begin{array}{c}\text { Ассиметрия, } \\
\mathrm{A}_{\mathrm{s \sigma}}\end{array}$ & $\begin{array}{c}\text { ККН, } \\
\text { мах }\end{array}$ \\
\hline С вибробоработкой & 8,85 & 120725 & 109,872 & $-1,11$ & 6,5 \\
\hline Без виброобработки & $-8,26$ & 16456,6 & 128,283 & $-1,2423$ & 12 \\
\hline
\end{tabular}


На наш взгляд, этот факт позволит рассмотреть данную технологию в будущем для разработки технологии снижения склонности к охрупчиванию хромистых сталей ферритного класса в интервале температур отпуска $400-500{ }^{\circ} \mathrm{C}$.

\section{Выводы}

Установлено, что вибрационная обработка не приводит к снижению качества формы сварного шва, снижает уровень сварочных деформаций, оказывает положительное действие на механические свойства металла шва.

Результаты определения остаточных напряжений в сварном шве при сварке пластин показывают, что на межоперационном цикле до проведения послесварочной термообработки уровень остаточных сварочных напряжений снижается в образцах, выполненных с вибрационной обработкой при частоте 50 Гц и амплитуде 0,4-0,6 мм, что позволяет снизить вероятность зарождения трещин при проведении операций отпуска и повторного нагрева в интервале температур $400-500{ }^{\circ} \mathrm{C}$.

\section{Список используемых источников}

1. Сомонов В.В. Изучение влияния параметров источника ультразвуковых механических колебаний и его расположения на образование колебаний в металле в области будущего сварного стыка и изменение микроструктуры в шве // Металлообработка. 2017. № 3 (99). C. 51-57.

2. Масаков В.В., Масакова Н.И., Мельзитдинова А.В. Сварка нержавеющих сталей. Тольятти: ТГУ, 2011. 184 с.

3. Каретников Д.В., Ризванов Р.Г., Файрушин А.М., Колохов К.С. Повышение надежности нефтегазового оборудования, работающего в условиях значительного перепада температур // Технология машиностроения. 2014. № 4. С. 33-37. 
4. Ризванов Р.Г., Файрушин А.М., Зарипов М.3., Карпов А.Л. Повышение качества изготовления сварных нефтехимических аппаратов применением вибрационной обработки в процессе сварки // Башкирский химический журнал. 2005. Т. 12. № 1. С. 27-29.

5. Файрушин А.М., Каретников Д.В., Салмин А.Н., Хаддад Д.А. О влиянии параметров вибрационной обработки на свойства металла сварного соединения // Нефтегазовое дело. 2011. Т. 9. № 2. С. 70-75.

6. Файрушин А.М. Совершенствование технологического процесса изготовления корпусов аппаратов с применением вибрационной обработки: дис. ... канд. техн. наук. Уфа: Изд-во УГНТУ, 2003. 121 с.

7. Ризванов Р.Г., Файрушин А.М., Каретников Д.В. Влияние параметров вибрационной обработки в процессе сварки на свойства сварных соединений // Литье и металлургия. 2012. № 3 (66). С. 337-342.

8. Пат. 2550673 РФ, МПК В 23 К 37/00. Устройство для оценки качества сварного шва / В.В. Панков, В.М. Букин, С.В. Панков, П.А. Крючков. 2013113394/02, Заявлено 25.03.2013; Опубл. 10.05.2015. Бюл. 13.

9. Ризванов Р.Г., Файрушин А.М., Карпов А.Л. Исследование технологической наследственности формирования отклонения формы сечения корпусов нефтегазохимических аппаратов // Международный Форум по проблемам науки, техники и образования: сб. тр. М.: Академия наук о земле, 2001. С. 32-34.

\section{References}

1. Somonov V.V. Izuchenie vliyaniya parametrov istochnika ul'trazvukovykh mekhanicheskikh kolebanii i ego raspolozheniya na obrazovanie kolebanii v metalle v oblasti budushchego svarnogo styka i izmenenie mikrostruktury v shve [The Study of the Influence of the Parameters of the Source of Ultrasonic Mechanical Oscillations and its Location on the Formation of Oscillations in the Metal in the Region of the Future Welded Joint and The Change in the Microstructure in the Seam]. Metalloobrabotka-Metalloobrabotka, 2017, No. 3 (99), pp. 51-57. [in Russian]. 
2. Masakov V.V., Masakova N.I., Melzitdinova A.V. Svarka nerzhaveyushchikh stalei [Welding of Stainless Steels]. Tolyatti, TGU Publ., 2011. 184 p. [in Russian].

3. Karetnikov D.V., Rizvanov R.G., Fairushin A.M., Kolokhov K.S. Povyshenie nadezhnosti neftegazovogo oborudovaniya, rabotayushchego $\mathrm{v}$ usloviyakh znachitel'nogo perepada temperatur [Improving the Reliability of Oil and Gas Equipment Operating in Conditions of Significant Temperature Differences]. Tekhnologiya mashinostroeniya - Tekhnologiya Mashinostroeniya, 2014, No. 4, pp. 33-37. [in Russian].

4. Rizvanov R.G., Fairushin A.M., Zaripov M.Z., Karpov A.L. Povyshenie kachestva izgotovleniya svarnykh neftekhimicheskikh apparatov primeneniem vibratsionnoi obrabotki v protsesse svarki [Improving the Manufacturing Quality of Welded Petrochemical Devices by Using Vibration Processing During the Welding Process]. Bashkirskii khimicheskii zhurnal - Bashkir Chemical Journal, 2005, Vol. 12, No. 1, pp. 27-29. [in Russian].

5. Fairushin A.M., Karetnikov D.V., Salmin A.H., Khaddad D.A. O vliyanii parametrov vibratsionnoi obrabotki na svoistva metalla svarnogo soedineniya [Influence of Vibration Treatment Con Dit Ions on Qualities of Welding Joints]. Neftegazovoe delo - Petroleum Engineering, 2011, Vol. 9, No. 2, pp. 70-75. [in Russian].

6. Fairushin A.M. Sovershenstvovanie tekhnologicheskogo protsessa izgotovleniya korpusov apparatov s primeneniem vibratsionnoi obrabotki: dis. kand. tekhn. nauk [Improvement of the Technological Process of Manufacturing Apparatus Bodies Using Vibration Processing: Cand. Engin. Sci. Diss.]. Ufa, UGNTU Publ., 2003. 121 p. [in Russian].

7. Rizvanov R.G., Fairushin A.M., Karetnikov D.V. Vliyanie parametrov vibratsionnoi obrabotki v protsesse svarki na svoistva svarnykh soedinenii [The Influence of Processing Parameters of Vibration During Welding on the Properties of Welded Joints]. Lit'e $i$ metallurgiya - Foundry Production and Metallurgy, 2012, No. 3 (66), pp. 337-342. [in Russian]. 
8. Pankov V.V., Bukin V.M., Pankov S.V., Kryuchkov P.A. Ustroistvo dlya otsenki kachestva svarnogo shva [Device for Assessing the Quality of the Weld]. Patent RF, No. 2550673, 2015. [in Russian].

9. Rizvanov R.G., Fairushin A.M., Karpov A.L. Issledovanie tekhnologicheskoi nasledstvennosti formirovaniya otkloneniya formy secheniya korpusov neftegazokhimicheskikh apparatov [Investigation of the Technological Heredity of the Formation of the Deviation of the Cross-Sectional Shape of the Bodies of Petrochemical Devices]. Sbornik trudov «Mezhdunarodnyi Forum po problemam nauki, tekhniki i obrazovaniya» [Proceedings «International Forum on Science, Technology and Education»]. Moscow, Akademiya nauk o zemle Publ., 2001, pp. 32-34. [in Russian].

\section{Сведения об авторах}

\section{About the authors}

Файрушин Айрат Миннуллович, канд. техн. наук, доцент, заведующий кафедрой «Оборудование и технологии сварки и контроля», УГНТУ, г. Уфа, Российская Федерация

Airat M. Fairushin, Candidate of Engineering Sciences, Associate Professor, Head of Equipment and Technologies for Welding and Control Department, USPTU, Ufa, Russian Federation

e-mail: otsk@ rusoil.net

Журихина Анастасия Витальевна, студент кафедры «Транспорт и хранение нефти и газа», УГНТУ, г. Уфа, Российская Федерация

Anastasia V. Zhurikhina, Student of Oil and Gas Transportation and Storage Department, USPTU, Ufa, Russian Federation

e-mail: steysi2000@mail.ru 
Бычков Владимир Александрович, студент кафедры «Транспорт и хранение нефти и газа», УГНТУ, г. Уфа, Российская Федерация

Vladimir A. Bychkov, Student of Oil and Gas Transportation and Storage Department, USPTU, Ufa, Russian Federation

e-mail: vellvostaree2012@yandex.ru

Салимзянова Диана Раилевна, студент кафедры «Оборудование и технологии сварки и контроля», УГНТУ, г. Уфа, Российская Федерация

Diana R. Salimzyanova, Student of Equipment and Technologies for Welding and Control Department, USPTU, Ufa, Russian Federation

e-mail: diana.2202@mail.ru 